\title{
An Emerging Chemical Fumigant: Two-Sided Effects of Dazomet on Soil Microbial Environment and Plant Response
}

\section{Ran Chen}

Shandong Agricultural University

\section{Weitao Jiang}

Shandong Agricultural University

\section{Shaozhuo Xu}

Shandong Agricultural University

\section{Hai Fan}

Shandong Agricultural University

\section{Xuesen Chen}

Shandong Agricultural University

\section{Xiang Shen}

Shandong Agricultural University

\section{Chengmiao Yin}

Shandong Agricultural University

zhiquan mao ( $\nabla$ mzhiquan@sdau.edu.cn )

Shandong Agricultural University https://orcid.org/0000-0001-6498-1299

\section{Research Article}

Keywords: Chemical fumigant-dazomet, soil physicochemical properties, soil microbial community structure, High-throughput sequencing, plant growth

Posted Date: May 11th, 2021

DOI: https://doi.org/10.21203/rs.3.rs-449045/v1

License: (c) (1) This work is licensed under a Creative Commons Attribution 4.0 International License. Read Full License

Version of Record: A version of this preprint was published at Environmental Science and Pollution Research on August 12th, 2021. See the published version at https://doi.org/10.1007/s11356-021-154014. 


\section{Abstract}

Methyl bromide has been banned worldwide because it causes damage to the ozone layer and the environment. To find a substitute for methyl bromide, the relationships among fumigation, plant growth, and the microbial community in replant soil require further study. We performed pot and field experiments to investigate the effects of dazomet fumigation on soil properties and plant performance. Changes in soil microbial community structure and diversity were assessed using high-throughput sequencing, and plant physiological performance and soil physicochemical properties were also measured. Dazomet fumigation enhanced photosynthesis and promoted plant growth in replant soil; it altered soil physical and chemical properties and reduced soil enzyme activities, although these parameters gradually recovered over time. After dazomet fumigation, the dominant soil phyla changed, microbial diversity decreased significantly, the relative abundance of biocontrol bacteria such as Mortierella increased, and the relative abundance of pathogenic bacteria such as Fusarium decreased. Over the course of the experiment, the soil microbial flora changed dynamically, and soil enzyme activities and other physical and chemical properties also recovered to a certain extent. This result suggested that the effect of dazomet on soil microorganisms was temporary. However, fumigation also led to an increase in some resistant pathogens, such as Trichosporon, that affect soil function and health. Therefore, it is necessary to consider potential negative impacts of dazomet on the soil environment and to perform active environmental risk management in China.

\section{Highlights}

- Fumigation of apple replant soil with dazomet renewed the soil microbial environment, improved soil physical and chemical properties, and dynamically restored soil ecological function.

- The activities of several soil enzymes and the relative abundance of beneficial microorganisms increased after dazomet fumigation. These changes were accompanied by higher rates of apple photosynthesis and growth.

- Fumigation reduced the content of pathogenic fungi such as Fusarium and increased the abundance of beneficial bacteria in the soil. However, it also increased the abundance of pathogenic bacteria such as Trichosporon, indicating that it is important to perform active environmental risk management.

\section{Introduction}

Planting the same crop every year can cause changes in the soil microflora and its predominant microorganisms (Aranda et al., 2011). This makes the soil vulnerable and leads to the deterioration of its physicochemical properties, the accumulation of plant autotoxins, a reduction in microbial diversity, and an increase in the abundance of pathogenic bacteria. Together, these factors lead to continuous cropping obstacles. Although the factors that give rise to continuous cropping obstacles are complex, they ultimately reflect an imbalance in the soil microbial ecological environment (Gil et al., 2009). 
The soil microbial community is widely considered to be an important indicator of soil environmental quality and plays an important role in nutrient cycling and the maintenance of soil structure (Degens et al., 2000; Schutter et al., 2001; Yao et al., 2000). Soil microbial diversity can reflect dynamic changes in the soil and provide information for the evaluation of soil function (Larkin et al., 2003). In a healthy soil environment, beneficial microorganism species are more abundant than pathogenic ones. Replant obstacles can damage soil microbial community structure and species diversity, promote the growth and accumulation of pathogenic microorganisms, inhibit the reproduction of beneficial microorganisms, and significantly reduce crop yield (Dong et al., 2016). Studying dynamic changes in soil microorganisms is useful for understanding their role in the prevention of replant obstacles in apple, thereby permitting the sustainable development of apple production. It also allows us to monitor the health status of the soil environment in real time, providing a scientific, theoretical basis for the maintenance of environmental safety.

At present, the most direct and efficient method of preventing soil-borne diseases is to fumigate the soil before a crop is planted (Deng et al., 2020). Methyl bromide has been the most widely used soil fumigant since 1940 (Zasada et al., 2010). However, it was listed under the Montreal Protocol as an ozonedepleting substance (ODS) and was phased out in developing countries by 2015 (EPA, 2009). The withdrawal of methyl bromide from use as an agricultural fumigant has prompted a great deal of research aimed at finding ecologically acceptable and economically viable alternatives. Dazomet is a recently developed broad-spectrum soil fumigant; it is converted in the soil to the active substance MITC, which will not destroy the ozone layer (Roberts \& Hutson, 1999). Furthermore, its soil retention time is short, making it more environmentally benign. With the elimination of methyl bromide, dazomet has been registered in many countries. Most importantly, its granular formulation is easier to use than liquid or gaseous fumigants, especially in areas where access to agricultural machinery is difficult (MBTOC, 2006). Most studies of dazomet have been performed in strawberry, tomato, flowers, ginger, cucumber, and other high-value crops (Mao et al., 2014; Mao et al., 2017) (Harris et al., 1991; Gilreath et al., 2004). It has also been reported that dazomet fumigation can promote the growth of Pinus densiflora and increase its yield (Cha et al., 2019). Studies have been performed to investigate the distribution and emission of dazomet after application (Nelson et al., 2013), to determine its degradation products (Ashworth and Yates, 2016), and to measure its residues (Maluin et al., 2020). However, few studies have examined the recovery of beneficial bacteria and pathogenic bacteria from the soil, the relationship between soil microorganisms and plant growth, and the relationship between environmental factors and changes in soil microbial community structure after dazomet fumigation. Such studies will not only provide theoretical guidance for agricultural production but will also allow us to better evaluate the impact of dazomet on the atmospheric ecological environment. Here, a 34-year-old apple orchard soil was fumigated with dazomet, and the physiological performance of Malus hupehensis Rehd. seedlings was observed over two years. Dynamic changes in soil bacterial and fungal communities, including changes in the relative abundance of beneficial and harmful bacteria, were monitored over the same period using high-throughput gene sequencing. The ability of dazomet to eliminate Fusarium solani in the replant soil was assessed using qPCR analysis, and changes in soil physical and chemical properties 
were documented after application. In addition, field experiments were performed to verify the effect of dazomet fumigation, and its impact on the field soil environment will continue to be studied in the future. We aim to provide scientific suggestions to promote sustainable and efficient apple production in the future while protecting the ecological environment.

\section{Materials And Methods}

\section{Experimental materials and design}

\section{Experiment l: Pot experiment}

The experiment was conducted at the College of Horticulture Science and Engineering, Shandong Agricultural University, National Apple Engineering Technology Research Center in $2019\left(36.16^{\circ} \mathrm{N}\right.$ $\left.117.15^{\circ} \mathrm{E}\right)$. The soil was obtained from a 34-year-old apple orchard in the village of Songjiezhuang $\left(36.09^{\circ} \mathrm{N} 117.04^{\circ} \mathrm{E}\right)$ in Tai'an City, Shandong. The rootstock was Malus micromalus Makino, and the test soil was collected randomly from the $10-40 \mathrm{~cm}$ depth after the removal of topsoil. Multi-point random sampling was used to sample the soil, and the soil was evenly mixed and air-dried prior to use. The soil type was a brown loam, and its basic physical and chemical properties are summarized in Table S1. The collected soil was treated with granular dazomet fumigant (hereafter referred to as DZ; Jiangsu Nantong Shizhuang Chemical Co., China) at the recommended rate of $600.0 \mathrm{~kg} \cdot \mathrm{hm}^{-2}$. The specific costs are shown in Table S2.

Seedlings of $M$. hupehensis (Pamp.) Rehd. var. pingyiensis (hereafter referred to as $M$. hupehensis), a common apple rootstock, were used as the test material (Qin et al., 2010). Seeds were stratified at $4{ }^{\circ} \mathrm{C}$ for approximately 40 days. After the seeds had become white, they were placed in a seedling tray in March 2019 for germination and growth.

The treatments were (1) untreated replant soil and (2) dazomet fumigated soil (DZ). On Apr. 17, 2019, soil was mixed with dazomet fumigant at the recommended dosage and sealed for 15 days for fumigation. The plastic film was then opened, and the treated soil was air-dried for seven days (Li et al., 2017), after which the soil was regularly turned to thoroughly remove any residual fumigant. Subsequent experiments were performed under natural conditions. On May 9, 2019, the seedlings had grown five true leaves, and seedlings of similar size and development were transplanted into clay tile pots (upper inner diameter 25 $\mathrm{cm}$, lower inner diameter $17 \mathrm{~cm}$, and height $18 \mathrm{~cm}$ ), each of which contained $7 \mathrm{~kg}$ of fumigated soil. Thirty pots were used for each treatment, and two seedlings were planted in each pot for unified fertilizer and water management. The same is true for untreated replanted soil.

\section{Experiment II: Field experiment}

The field experiment was conducted from March to October 2020 in the village of Wantou $\left(37.09^{\circ} \mathrm{N}\right.$ $\left.119.80^{\circ} \mathrm{E}\right)$ in Laizhou City, which is located in Yantai City in Shandong Province, China. The treatments were (1) untreated replant soil and (2) dazomet fumigated soil (DZ). Twenty-five-year-old trees were 
removed from the orchard in March 2020, after which dazomet fumigation was applied and the orchard was replanted. Healthy two-year-old young apple trees of similar size $(\sim 1 \mathrm{~cm}$ stem diameter) were selected; their rootstock was T337 and their scion was Yan fu 3 (hereafter referred to as young apple trees). The graft in a spindle shape was uniformly pruned to $1.4 \mathrm{~m}$ above the ground. The row spacing was $1.5 \mathrm{~m} \times 4.0 \mathrm{~m}$. The young apple trees were spaced $4 \mathrm{~m}$ apart in rows and $1.5 \mathrm{~m}$ apart in plants. Each treated 30 trees, covering an area of about 0.018 hectares. The specific costs are shown in Table S2.

\section{Soil sampling}

Pot experiment. Soil samples were collected and measured on May 2, 2019 ( 0 days after fumigation, hereafter referred to as period A), Sept. 10, 2019 (period B), and Sept. 10, 2020 (period C). On each sampling date, three replicate pots were randomly selected from each treatment for measurement. During sampling, soil was removed around the basin and the surface layer, sifted through a 2-mm sieve, and placed into three sealed bags. One bag was stored in a freezer at $-20^{\circ} \mathrm{C}$ for measurement of soil nutrient $\mathrm{NO}_{3}{ }^{-}-\mathrm{N}$ and $\mathrm{NH}_{4}{ }^{+} \mathrm{N}$ contents. Another bag was immediately placed into liquid nitrogen and stored in a $-80{ }^{\circ} \mathrm{C}$ freezer for later analysis of soil microbial community structure, DNA extraction, and real-time fluorescence quantitative PCR. The last bag was naturally air-dried for the measurement of soil enzyme activity, available phosphorus, available potassium, and organic matter. At the same time, three seedlings of $M$. hupehensis were collected at periods B and C. After washing, the seedlings were used for measurement of plant height, diameter at ground height, fresh weight, and dry weight.

Field experiment. Six young apple trees were randomly selected for each treatment. Plant growth indices (plant height, stem diameter, number of branches, branch length) were measured on July 15, 2020 and Oct. 15, 2020.

\section{Measurement of MITC concentrations in soil}

MITC was extracted from the soil and its concentration was determined by HS-GS (headspace gas chromatography). Wage out about $1 \mathrm{~g}$ sample, add $2 \mathrm{~mL} 50 \mathrm{mM}$ PBS buffer solution (phosphoric acid buffer salt solution), and plug the rubber plug. The gas-liquid equilibrium was achieved on the headspace sampler (North Divide Rayleigh, F-502) for 20min. The upper gas was taken and injected into gas chromatography (North Divide Rayleigh gas chromatograph 3420A) for detection. HS-GS Specific conditions: First, turn on the computer, carrier gas, air source generator, hydrogen generator and gas phase host. Then open the software BF-2002(general version), and set the inlet temperature of $150^{\circ} \mathrm{C}$, detector temperature of $260^{\circ} \mathrm{C}$, and column temperature of $60^{\circ} \mathrm{C}$ in the method group. Set according to the heating procedure in Table 1. After setting the saving method group, the method is sent to the instrument. Second, the headspace sampler setting: Headspace cylinder temperature: $80^{\circ} \mathrm{C}$, quantitative ring: $115^{\circ} \mathrm{C}$, transmission line temperature: $120^{\circ} \mathrm{C}$. Equilibrium time $20 \mathrm{~min}$. Finally, when the instrument three temperatures have reached the set value, the ignition of the instrument. After the ignition is successful, the baseline will be monitored. After the baseline is stable for $30 \mathrm{~min}$, the injection needle will 
be started. After the injection and before the injection of each sample, the injection needle shall be purged.

Table 1 Heating procedure

\begin{tabular}{|llll|}
\hline $\mathrm{T} /{ }^{\circ} \mathrm{C}$ & Heating rate $/{ }^{\circ} \mathrm{C} / \mathrm{min}$ & Hold $/$ min & Total time/min \\
\hline 60 & 0 & 2 & 2 \\
\hline 100 & 10 & 2 & 8 \\
\hline 240 & 30 & 5 & 17.6 \\
\hline
\end{tabular}

\section{Measurement of soil physicochemical properties and enzyme activity}

Pot experiment. On each sampling date, rhizosphere soil samples of three $M$. hupehensis seedlings were collected from each treatment and immediately placed into ziplock bags and frozen at $-20{ }^{\circ} \mathrm{C}$. After leaching $6 \mathrm{~g}$ of soil with $50 \mathrm{~mL}$ of $1 \mathrm{M} \mathrm{KCL}$, the contents of $\mathrm{NO}_{3}{ }^{-}-\mathrm{N}$ and $\mathrm{NH}_{4}{ }^{+}-\mathrm{N}$ in soil were determined using an AA3 automatic flow analyzer (Model AA3-A001-02E, Bran-Luebbe, Germany) (Xue et al., 2017). Available potassium was extracted with $1 \mathrm{M} \mathrm{CH}_{3} \mathrm{COONH}_{4}$ and analyzed using a flame photometer (Model 410, Sherwood Co., England) (Sharma et al., 2018). Available phosphorus was extracted with $0.5 \mathrm{M}$ $\mathrm{NaHCO}_{3}$ and analyzed using a Discrete Auto-analyzer (Smart Chem 200, Alliance Co., France) (Zheng et al., 2016). The organic matter content $\left(5.60 \mathrm{~g} \mathrm{~kg}^{-1}\right)$ was determined by the potassium dichromate method (Wu and Chen, 2016).

Soil urease activity was determined by a colorimetric assay using sodium phenate-sodium hypochlorite; soil phosphatase activity was determined by a colorimetric assay with disodium phenyl phosphate; soil sucrase activity was determined by a colorimetric assay with 3,5-dinitrosalicylic acid; and soil catalase activity was determined by potassium permanganate titration (Du et al., 2017). Please refer to the supplementary data for details.

\section{DNA extraction and real-time quantitative analysis of Fusarium solani}

Pot experiment. The extraction and purification of total genomic DNA from the sampled soil were performed following the instructions of the E.Z.N.A. Soil DNA Kit (Omega Bio-tek, Norcross, GA, USA). The CFX Connect system (BIO-RAD, Hercules, CA, USA) was used to analyze the copy number of Fusarium solani gene in the soil by real-time quantitative PCR. The primers are FR (5'-GGCCTGAGGGTTGTAATG-3') and FF (5'-CGAGTTATACAACTCATCAACC-3'). The reactions were performed according to the instructions of the SYBR Premix Ex Taq Kit (TaKaRa Biotech Co., Ltd., Dalian, China). Each reaction in the 25- $\mu \mathrm{L}$ PCR system included $1.5 \mu \mathrm{L}$ of DNA template, $12.5 \mu \mathrm{L}$ of SYBR Premix Ex Taq II (TaKaRa), $1 \mu \mathrm{L}$ of each primer, and $9 \mu \mathrm{L}$ of double distilled water. The reaction procedures were pre-denaturation at $95^{\circ} \mathrm{C}$ for $30 \mathrm{~s}$, denaturation at $95^{\circ} \mathrm{C}$ for $5 \mathrm{~s}$, and annealing at $60^{\circ} \mathrm{C}$ for $30 \mathrm{~s}$, for a total of 40 cycles.

\section{Measurement of plant physiological indices}


Pot experiment. On each sampling date, three $M$. hupehensis seedlings were harvested from each treatment and washed in clean water. Measurements of seedling height, diameter at ground height, and fresh mass were obtained using a ruler, vernier caliper, and electronic scale, respectively. After these measurements, the seedlings were wrapped tightly in paper bags and placed in a constant temperature oven. After drying, seedlings were carefully removed, and their dry masses were measured with an electronic scale. All measurements were performed between 08:30 and 11:30 on Sep. 10, 2019 and Sep. 10,2020 . During the measurement period, the relative humidity of the air was approximately $75 \%$, the leaf temperature was $28^{\circ} \mathrm{C}$, and the ambient $\mathrm{CO}_{2}$ concentration was $320-390 \mu \mathrm{mol} \mathrm{mol}^{-1}$. The net photosynthetic rate $\left(P_{\mathrm{n}}\right)$, stomatal conductance $\left(G_{\mathrm{s}}\right)$, transpiration rate $\left(T_{\mathrm{r}}\right)$, and internal $\mathrm{CO}_{2}$ concentration $\left(C_{\mathrm{i}}\right)$ were measured on fully expanded leaves using a portable photosynthesis system (CIRAS-3, PP Systems, Amesbury, MA, USA). These measurements were made on five randomly selected seedlings (two leaves per seedling) from each of three replicate blocks of each treatment.

Field experiment. On each sampling date, six replicate young apple trees were randomly selected for growth index measurement. Plant height and branch length were measured using a measuring tape, and stem diameter was measured using vernier calipers. The final results are the average of six replicates.

\section{High-throughput sequencing of soil fungi andbacteria}

Pot experiment. Total DNA was extracted from each soil sample using the E.Z.N.A. Soil DNA Kit (Omega Bio-tek Inc., Norcross, USA) according to the manufacturer's protocols. The final DNA concentration and purification were determined using a Nano Drop 2000 UV-vis spectrophotometer (Thermo Scientific, Wilmington, USA), and DNA quality was checked by $1 \%$ agarose gel electrophoresis. PCR amplification was carried out using a Thermocycler PCR system (Gene Amp 9700, ABI, USA). The V3-V4 hypervariable regions of the 16S rRNA gene were amplified with bacterial primers 338F 5'-ACTCCTACGGGAGGCAGCAG3 ' and 806R 5'-GGACTACHVGGGTWTCTAAT-3' (Chen et al., 2018). Fungal rRNA gene amplification was performed in the fungal ITS sequence region using the barcode primers ITS1F5'-

CTTGGTCATTTAGAGGAAGTAA-3' and ITS2R5'-GCTGCGTTCTTCATCGATGC-3' (Chen et al., 2018). The resulting PCR products of bacteria and fungi were extracted from a $2 \%$ agarose gel, further purified using the AxyPrep DNA Gel Extraction Kit (Axygen Biosciences, USA) and quantified using QuantiFluor-ST (Promega, USA) according to the manufacturer's protocol.

\section{Illumina MiSeq sequencing and data processing}

The bacteria and fungi PCR products were purified and pooled in equimolar amounts and paired-end sequenced $(2 \times 300)$ on an Illumina MiSeq platform (IIlumina, San Diego, USA) according to the standard protocols by Majorbio Bio-Pharm Technology Co., Ltd. (Shanghai, China). Raw fastq files of bacterial and fungal reads obtained from MiSeq sequencing were quality-filtered by Trimmomatic and merged by FLASH (Magoc and Salzberg, 2011; Bolger et al., 2014; Gdanetz et al., 2017). The processed sequences were subsequently clustered into operational taxonomic units (OTUs) with a minimum of $97 \%$ similarity using UPARSE (version 7.1) (Gdanetz et al., 2017). The taxonomy of the bacterial sequence was analyzed 
by the RDP Classifier algorithm against the SILVA database (version 128/16S-bacteria database) with a confidence threshold of $70 \%$. The taxonomy of the fungal sequence was analyzed by the RDP Classifier algorithm against the United States database (version 7.0/ its-fungi database) using a confidence threshold of $70 \%$. Potential functional changes of the bacterial community in the soil samples were predicted using Phylogenetic Investigation of Communities by Reconstruction of Unobserved States (PICRUSt) (Huang, 2019). The raw reads were deposited into the NCBI Sequence Read Archive (SRA) database (Accession Number: SRP313044).

\section{Bioinformatics and Statistical Analysis}

Analysis considered on the biological data that met quality control standards. Based on specific thresholds (default selection 97\%), operational taxonomic unit (OTU) clustering, and the SILVA database, which is the most authoritative database of microbial species and species classification annotation. Based on the Bray-Curtis distance metric at the genus level can determine the beta diversity indices of the samples. We used the Shannon and Chao indices to statistical analyse alpha diversity with Mothur (version 1.30.1). Most statistical and mapping analyses, such as the species composition analysis (Heatmap), Circos samples and species relationships analysis, species abundance analysis between groups by the t-test, and redundancy (RDA)/canonical correspondence (CCA) analysis to reflect the relationship between microbial community and environmental factors, were performed with $\mathrm{R}$ software (version 3.3.1). Standard error was performed with SPSS software (version 19.0, SPSS Inc., Chicago, USA). Statistical analysis was performed using Microsoft Excel office2019 and GraphPad Prism 8.0 (San Diego, CA 92108, USA). A t-test was used to assess the significance of differences between the two treatments on a given date. $P<0.05$ was considered a statistically significant difference.

\section{Results}

\section{Determination of MITC concentrations}

In this study, after DZ fumigation, according to the calculation in Fig. 1, the concentration level of MITC in the soil was lower than the detection limit (Table 2).

Table 2

Determination of MITC concentrations

\begin{tabular}{|lll|}
\hline Sample name & Sample weight $(\mathbf{g})$ & MITC concentrations $(\boldsymbol{\mu g} / \mathbf{g ~ F W})$ \\
\hline DZ1 & 1.1577 & 0.4676 \\
\hline DZ2 & 1.1214 & 0.4686 \\
DZ3 & 1.1233 & 0.4739 \\
\hline
\end{tabular}

Notes: DZ1, DZ2, and DZ3 refer to the three duplicate samples in 5/2019 (Period A), respectively. 
At period $C$, the contents of ammonium nitrogen (Figure 2a), nitrate nitrogen (Figure 2b), available potassium (Figure 2c), available phosphorus (Figure 2d), and organic matter (Figure S1a) in the DZ soil were $19.32 \%, 8.37 \%, 7.33 \%, 42.40 \%$, and $2.37 \%$ higher, respectively, than those in the control soil. After fumigation, soil enzyme activities decreased significantly, but they gradually recovered with time. At period $C$, the activities of phosphatase (Figure 3a), sucrase (Figure $3 b$ ), urease (Figure $3 c$ ), and catalase (Figure $3 \mathrm{~d}$ ) had increased by $2.28 \%, 15.58 \%, 3.89 \%$, and $7.12 \%$, respectively.

\section{Effect of dazomet fumigation on gene copy number of Fusarium solani}

Compared with the control soil, the number of $F$. solanigene was significantly lower in DZ fumigated soil (Figure S2b). F. solani gene copy number decreased by $91.19 \%$ in period A, $67.31 \%$ in period B, and $54.19 \%$ in period C. Clearly, the gene copy number of $F$. solani recovered with time. Differences in gene copy number between DZ and control soil were significant throughout all sampling periods.

\section{Effects of dazomet fumigation on soil microbial diversity}

After quality filtering, a total of 1,040,498 fungal and 1,027,441 bacterial effective sequences were obtained from all samples and were clustered into 551 fungal OTUs and 2558 bacterial OTUs. After dazomet fumigation, the Chao diversity index of fungi decreased temporarily and was lower than that of control soil, although it did not differ significantly between the soils (Figure 4a, $p=1.08 \times 10^{-1}, p=$ $2.83 \times 10^{-1}$, and $p=1.87 \times 10^{-1}$ for CKA-DZA, CKB-DZB, and CKC-DZC, Student's $t$-test,). However, the Shannon richness index of the fungal community was significantly higher in the dazomet-treated soil than in the control soil through Sept. 2020 (Figure 4b, $p=1.15 \times 10^{-3}, p=1.78 \times 10^{-2}, p=8.93 \times 10^{-3}$ for CKA-DZA, CKB-DZB, and CKC-DZC, Student's $t$-test). On the first sampling date, the Chao diversity index for bacteria was lower in the dazomet-treated soil than in the control soil $\left(p=7.10 \times 10^{-6}, \mathrm{CKA}-\mathrm{DZA}\right.$, Student's $t$-test). The Chao diversity index for bacteria increased gradually over time and was higher in dazomet soil than in control soil on later sampling dates (Figure 4c, $p=2.76 \times 10^{-2}, p=1.26 \times 10^{-1}$, CKBDZB and CKC-DZC, Student's $t$-test). The Shannon richness index of the bacterial community was significantly lower in dazomet-treated soil through Sept. 2020 (Figure 4d, $p=2.46 \times 10^{-4}, p=4.43 \times 10^{-2}$, $p=1.20 \times 10^{-2}$, CKA-DZA, CKB-DZB, and CKC-DZC, Student's $t$-test).

PC1 and PC2 are the two main coordinate components in PCoA. PC1 and PC2 accounted for $49.96 \%$ and $17.28 \%$ of the difference in fungal species composition among different treatments. Periods $A$ and $B$ after fumigation were located far from the control on PC1 (Figure 4e). The distance between treatments from different sampling periods reached statistical significance, and the distance between control and dazomet-treated soil in periods A and B also reached the level of alpha $=0.05$. PC1 and PC2 accounted for $53.81 \%$ and $22.36 \%$ of the difference in bacterial species composition among different treatments. Periods $A$ and $B$ after fumigation were located far from the control (Figure 4f). In period C, the distance between dazomet and control soil was not statistically significant. These results indicated that microbial community diversity changed dynamically over time after fumigation; the initial community diversity recovered gradually in dazomet-treated soil and did not differ significantly from that of the control group. 


\section{The influence of dazomet fumigation on soil microbial community structure}

We used heatmaps to analyze the 25 most abundant fungal genera (Figure $5 a$ ). The abundances of these 25 dominant genera differed slightly among different time periods within the same treatment. After replant soil was treated with dazomet, Mortierella, Trichoderma, Exophiala, and Trichosporon were dominant in period A; Rhizophagus and Phoma were dominant in period B; and Kernia, Fusarium, and Mortierella were dominant in period C. As shown in Fig. S2a, the fungi were distributed among 5 phyla, 91 families, and 158 genera in period A; 6 phyla, 100 families, and 178 genera in period B; and 7 phyla, 103 families, and 176 genera in period C. Ascomycota (65.43\% of all sequence reads), Basidiomycota (23.81\%), and Zygomycota (10.60\%) were the most abundant phyla in period A; Ascomycota $(66.57 \%)$, Chytridiomycota (12.68\%); and Basidiomycota (11.98\%) were most abundant in period B; and Ascomycota (77.30\%), Basidiomycota (10.44\%), and Zygomycota (6.54\%) were most abundant in period C. The average proportion of Ascomycota increased from $65.43 \%$ to $77.30 \%$ over time in dazomet-treated soil, and it was significantly lower than that of the control. The relative abundance of Basidiomycota decreased from $23.81 \%$ to $10.44 \%$, and it was significantly higher in dazomet-treated soil than in control soil. The relative abundance of Zygomycota and Rozellomycota in dazomet-treated soil increased in the second year compared with the first year, whereas the relative abundance of Chytridiomycota and Glomeromycota declined in the second year.

We used heatmaps to analyze the 25 most abundant bacterial genera (Figure 5b). After dazomet fumigation, Pseudomonas, Methyloversatilis, and Bacillus were dominant in period A; Sphingomonas and Nocardioides were dominant in period B; and Pseudarthrobacter and RB41 were dominant in period C.

The composition of dominant phyla was similar in different sampling periods (Figure S2a). Bacteria were divided into 28 phyla, 327 families, and 644 genera in period A; 32 phyla, 366 families, and 747 genera in period B; and 36 phyla, 418 families, and 837 genera in period C. Proteobacteria (68.70\%), Firmicutes (14.32\%), Actinobacteria (7.43\%), and Chloroflexi (7.11\%) were the dominant phyla in period B; Proteobacteria (30.31\%), Chloroflexi (18.45\%), Firmicutes (16.10\%), and Actinobacteria (12.39\%) were dominant in period B; and Proteobacteria (20.16\%), Chloroflexi (18.03\%), Actinobacteria (16.78\%), and Acidobacteria (15.45\%) were dominant in period C. Over the sampling period, the relative abundance of Proteobacteria decreased from $68.70 \%$ to $20.16 \%$ in dazomet-treated soil, Chloroflexi increased from $7.11 \%$ to $18.03 \%$, Actinobacteria increased from $7.43 \%$ to $16.78 \%$, and Firmicutes showed little change. Interestingly, the relative abundance of Acidobacteria increased from $0.86 \%$ in period A to $15.45 \%$ in period $\mathrm{C}$ and did not differ significantly between fumigated and control soil.

\section{Analysis of species diversity of soil microorganisms after dazomet fumigation}

Linear discriminant analysis effect size (LEfSe) analysis was used to identify the biomarkers that caused significant differences between dazomet-treated and control soil for different microbial classifications in different periods $(p<0.05, \mathrm{LDA}=4$; Figure 5a-d). For fungi (Figure 6a), 29 biomarkers were generated in period A (24 for DZ); 17 biomarkers were generated in period B (13 for DZ); and 17 biomarkers were generated in period $C$ ( 9 for DZ). For bacteria (Figure $6 b$ ), 35 biomarkers were generated in period $A$ (18 
for DZ); 23 biomarkers were generated in period B (18 for DZ); and 23 biomarkers were generated in period C (10 for DZ). Figure S3 shows the significance test for differences between groups at the species level. For fungi (Figure S3a) after fumigation, the relative abundance of Pseudallescheria sp, Kernia pachypleura, F. solani, and G. reesii decreased significantly compared with the control, and the relative abundances of the remaining species were significantly higher in dazomet-treated soils than in control soils. For bacteria (Figure S3b) after fumigation, the relative abundance of Turicibacter sp. H121, Romboutsia ilealis, and Clostridium butyricum was significantly lower in dazomet-treated soil than in control soil. Caulobacter vibrioides and Herbaspirillum seropedicae were the two dominant species with the highest relative abundance after fumigation. As time passed, the relative abundance of these species decreased significantly and did not differ from that in control soil.

\section{Correlation of soil microorganisms with environmental factors after dazomet fumigation}

The results of redundancy analysis (RDA)/canonical correspondence analysis (CCA) revealed the relationship between microbial community composition and levels of soil $\mathrm{P}, \mathrm{K}, \mathrm{NO}_{3}{ }^{-}-\mathrm{N}$, and $\mathrm{NH}_{4}{ }^{+} \mathrm{N}$. All of the edaphic variables explained $72.66 \%$ of the variance; RDA1 explained $63.93 \%$ of the variance, and RDA2 explained another $8.73 \%$ (Figure 7a). The major soil biochemical characteristics that drove soil fungal community composition were $\mathrm{P}\left(r^{2}=0.69, p=0.001\right), \mathrm{K}\left(r^{2}=0.95, p=0.001\right), \mathrm{NO}_{3}{ }^{-}-\mathrm{N}\left(r^{2}=0.74, p=\right.$ $0.001), \mathrm{NH}_{4}{ }^{+}-\mathrm{N}\left(r^{2}=0.96, p=0.001\right)$, and organic matter $\left(r^{2}=0.07, p=0.603\right)$. Together, all the edaphic variables explained $82.04 \%$ of the variance; RDA1 explained $73.03 \%$, and RDA2 explained another $9.01 \%$ (Figure $7 \mathrm{~b}$ ). The major soil biochemical characteristics that drove soil bacterial community composition were $\mathrm{P}\left(r^{2}=0.71, p=0.001\right), \mathrm{K}\left(r^{2}=0.97, p=0.001\right), \mathrm{NO}_{3}{ }^{-} \mathrm{N}\left(r^{2}=0.91, p=0.001\right)$, and $\mathrm{NH}_{4}{ }^{+}-\mathrm{N}\left(r^{2}=0.95, p\right.$ $=0.004)$. In period $A$, organic matter was the main factor that affected the composition of the bacterial and fungal communities (Figure 7). In periods $B$ and $C$ (Figure 7a), the main factors that affected fungal community composition were $\mathrm{NH}_{4}{ }^{+}-\mathrm{N}$ and $\mathrm{K}$, followed by P. In period B (Figure 7b), the main factors that affected bacterial community composition were $\mathrm{NO}_{3}{ }^{-}-\mathrm{N}^{-}$and $\mathrm{NH}_{4}{ }^{+}-\mathrm{N}$, followed by P. In period C (Figure 7b), there were almost no correlations between soil microorganisms and environmental factors.

\section{Physiological indices of $M$. hupehensis seedlings and young apple trees}

Dazomet fumigation significantly increased the biomass of $M$. hupehensis seedlings in period $\mathrm{B}$ (Table S3). Compared with the control, the plant height, stem diameter, fresh weight, and dry weight of seedlings in the dazomet treatment increased by $69.93 \%, 124.86 \%, 65.02 \%$, and $65.39 \%$, respectively. In period C, these parameters were still $29.68 \%, 48.92 \%, 35.07 \%$, and $28.33 \%$ higher in the dazomet treatment than in the control. In the field experiment in Oct. 2020 (Table S4), plant height, stem diameter, branch number, and branch length of the young apple trees were $24.78 \%, 24.75 \%, 64.25 \%$, and $148.71 \%$ higher, respectively, in the dazomet treatment than in the control.

\section{Chlorophyll content and leaf photosynthetic parameters of $M$. hupehensis seedlings}


Compared with the control, the leaves of $M$. hupehensis seedlings from the dazomet treatment had significantly more chlorophyll a, chlorophyll b, and carotene (Table S5). In period B, chlorophyll a, chlorophyll $b$, and carotene levels were $1.43,1.79$, and 1.25 times higher in the dazomet treatment than in the control group. In period C, these parameters were 1.39, 1.93, and 1.36 times higher in the dazomet treatment. $P_{n}, G_{s}, T_{r}$, and $C_{i}$ were also higher in seedling leaves of the dazomet treatment (Figure S5). In period $B, P_{n}, G_{s}, T_{r}$, and $C_{i}$ were $1.60,1.32,1.56$, and 1.00 times higher, respectively, in the dazomet treatment than in the control. In period $C$, these parameters were 1.71, 1.44, 1.50, and 1.03 times higher in the dazomet treatment.

\section{Discussion}

The soil environment refers to the soil layer that continuously covers the earth's land surface, and the use of soil fumigant to alleviate replant obstacles directly affects the soil environment. Dazomet fumigant is a preferred substitute for methyl bromide because of its low toxicity, good biocide effect, and long-lasting efficacy. it is converted in the soil to the active substance MITC, which will not destroy the ozone layer (Roberts \& Hutson, 1999). Fang et al. (2020) found that the degradation half-life of dazomet fumigant in a Beijing soil ranged from 29 to $86 \mathrm{~h}$, and MITC could not be detected 7 days after fumigation. The current studies suggested that dazomet fumigant had no negative effects on the external environment or the ozone layer.

It is well known that soil physical and chemical properties are important measures of soil health. Here, soil physicochemical properties were altered after fumigation of apple replant soil. Ammonium nitrogen and nitrate nitrogen are the main forms of nitrogen in soil (Ayankojo et al., 2020). These nitrogen forms can be transformed by nitrification and denitrification, and nitrification is one of the most important processes of soil nitrogen transformation. We found that soil $\mathrm{NH}_{4}{ }^{+} \mathrm{N}$ content increased after dazomet fumigation, whereas soil $\mathrm{NO}_{3}{ }^{-}-\mathrm{N}$ content decreased. This pattern may be explained by the fact that dead soil microorganisms decompose to produce a large amount of $\mathrm{NH}_{4}{ }^{+}-\mathrm{N}$ after fumigation (Yamamoto et al., 2008). In addition, soil fumigation may also depress microbiological nitrification and affect the conversion of $\mathrm{NH}_{4}{ }^{+}-\mathrm{N}$ to $\mathrm{NO}_{3}{ }^{-}{ }^{-} \mathrm{N}$, leading to $\mathrm{NH}_{4}{ }^{+}-\mathrm{N}$ accumulation and decreases in $\mathrm{NO}_{3}{ }^{-} \mathrm{N}$ (Yan et al., 2015). The contents of $\mathrm{NH}_{4}{ }^{+}-\mathrm{N}$ and $\mathrm{NO}_{3}{ }^{-} \mathrm{N}$ in each treatment generally decreased over time, possibly because $M$. hupehensis entered a rapid growth period and its absorption capacity gradually increased, but they were always higher in the dazomet treatment than in the control. Dazomet fumigation increased available phosphorus and available potassium contents of the soil but had little effect on organic matter content. This may have been because fumigation changes the rate of soil microbial metabolism, and microbial metabolism and reproduction affect soil conditions, nutrient accumulation, and nutrient cycling (Ingram et al., 2005).

Soil enzyme activity is an important factor for evaluating the level of materials in soil, energy metabolism, and soil quality (Shao et al., 2015). Du et al. (2017) found that soil enzyme activity was altered after fumigant application. Soil fumigation also led to a decline in soil microbial activity, thereby causing a 
decrease in soil enzyme activity (Nannipieri et al., 2012). However, soil enzyme activity gradually recovered with time. In this study, dazomet fumigation significantly reduced the urease, sucrase, phosphatase, and catalase activities of replant soil, but as time progressed, the magnitudes of these changes differed. This pattern may stem from the fact that fumigation can kill soil microorganisms to some extent, but as the beneficial microbes recover, so does enzyme activity. This is consistent with the results of Zhang et al. (2019).

Soil microorganisms are responsible for many biological aspects of soil health in terrestrial ecosystems, and when microbial ecology is disturbed, soil biological processes are affected (Friedrich, 2011). Longterm soil replant obstacles can seriously impair the health of the soil environment; microbial community structure is altered, and the microecological balance is damaged, transforming the soil environment from a "bacterial" type to a "fungus" type (Guo et al., 2014). Numerous studies have shown that Fusarium, Trichosporon, Cylindrocarpon, and Pythium are the main causes of replant obstacles in apple-producing countries such as the United States, Italy, and South Africa (Mazzola et al., 1998; Manici et al., 2003; Schoor et al., 2009). Wang et al. (2018) found that Fusarium fungi were the main pathogens responsible for apple replant obstacles in the Bohai Bay area in China. Here, we found that dazomet fumigation significantly reduced the gene copy number of $F$. solani, although $F$. solani gradually recovered over time. This result shows that fumigants do not have a sustained, direct, toxic effect on overall microbial metabolic activity and biomass (Fang et al., 2019). After fumigation, the relative abundance of the pathogenic fungus Trichosporon was higher in dazomet-treated soils than control soils. Clearly, fumigation may not kill all soil pathogens, and some pathogens with strong resistance may absorb nutrients contained in the fumigant itself and temporarily proliferate. Interestingly, the abundance of Exophiala increased after fumigation. Studies have shown that this fungus can colonize plant roots to alleviate the toxic effects of excess metal ions in the soil microenvironment around plant roots (Zhang et al. 2012). This result suggested that Exophiala can be used as a beneficial fungus to promote plant growth. At the species level, Pseudallescheria sp. and Kernia pachypleura, as the dominant species with the highest abundance in replant soils, both belong to the Ascomycetes (Su et al., 2020). Dazomet fumigation significantly reduced their abundance. Pinto et al. (2004) and Su et al. (2020) reported that Pseudallescheria is an emerging fungal pathogen with a worldwide distribution, and Pseudallescheria sp. and $K$. pachypleura may be responsible for replant obstacles. Dazomet fumigation significantly inhibited soil fungal diversity and altered the dominant microbial populations, consistent with the results of Li et al. (2017).

Soil bacteria interact with plants, using rhizosphere secretions as a source of nutrients, and thereby affect plant growth (Bulgarelli et al., 2013). We observed that dazomet fumigation had a marked effect on the diversity of the soil bacterial community, and the relative abundance of dominant bacterial groups changed with the restoration of the soil environment. Previous studies have reported that fumigants create a short "ecological vacuum period" by temporarily reducing the number of bacteria; as a result, some beneficial bacteria-and even harmful microorganisms-rapidly take advantage and colonize the soil (Yakabe et al., 2010). In this study, Proteobacteria and Firmicutes quickly became the dominant phyla after fumigation. Over time, the abundance of Proteobacteria gradually decreased, and Actinobacteria 
and Chloroflexi gradually became the dominant phyla. At the genus level, the relative abundance of Pseudomonas, Methyloversatilis, and Bacillus was high after fumigation. Pseudomonas and Bacillus are effective biological control agents and produce antibiotics that reduce soil disease (Hollister et al., 2013). They can also increase plant disease resistance (Widnyana and Javandira, 2016), degrade soil pollutants (Rabodonirina et al., 2019), and inhibite increases in pathogen numbers (Mehrabi et al., 2016; Huang et al., 2018). Interestingly, fumigation was associated with the dominance of Pseudomonas spp. collectively known as plant growth promoting rhizobacteria (PGPR), which have been shown to promote plant growth (Pii et al., 2015). Such changes may have been beneficial to the growth of $M$. hupehensis seedlings, which showed increased leaf chlorophyll content and photosynthetic parameters. Sphingomonas also gradually became dominant over time. Sphingomonas is considered to be a beneficial bacterium because it breaks down organic pollutants and releases antibiotics into the soil. At the species level, we found that Caulobacter vibrioides and Herbaspirillum seropedicae were the two dominant species with the highest abundance after fumigation. Both $C$. vibrioides and $H$. seropedicae belong to the genus Firmicutes, which demonstrates rapid profileration and produces spores with strong resistance to adverse conditions (Scott et al., 2018). Among the Firmicutes, $C$. vibrioides can produce the plant hormone IAA and promote plant growth (Wang et al., 2016). However, the abundance of these two strains decreased in the later period, perhaps because of antagonism from increasing numbers of bacterial species that recovered later, which may have prevented them from multiplying in large numbers. These results are not consistent with the assertion that soil fumigation does not significantly alter the dominant flora in the bacterial community (Liu et al., 2015). Interestingly, dazomet fumigation not only altered soil microbial diversity and dominant populations but also produced a significant correlation between soil environmental factors and soil microbial community composition. Nitrate nitrogen and ammonium nitrogen were the main factors that affected the composition of the bacterial community, possibly because fumigation inhibited microbial nitrification, thereby causing the dynamic mutual transformation of nitrifying and denitrifying soil bacteria (Yan et al., 2017).

\section{Conclusions}

In this study, we treated replant soil with dazomet fumigant and studied soil microbial parameters, soil physiological and biochemical properties, plant growth and physiology, and the relationship between soil microorganisms and environmental factors over the following two years. Fumigation increased the contents of available phosphorus, available potassium, ammonium nitrogen, nitrate nitrogen, and organic matter. It increased the abundance of beneficial microorganisms such as Mortierella, Pseudomonas, and Exophiala and decreased the abundance of pathogenic fungi such as $F$. solani, while also decreasing soil enzyme activities. Over time, the diversity of bacteria and fungi in dazomet-treated soil first decreased and then gradually increased until it was higher than that of the control group. The structure of the soil microbial community also recovered over time, and soil enzyme activity gradually increased and was higher than that of the control group, promoting the restoration of soil ecological health. The direct effect of soil microbial environmental changes in the pot experiment was to significantly promote the growth of $M$. hupehensis seedlings, increase photosynthesis, and regulate the balance of the atmospheric 
environment. Field experiments confirmed that dazomet fumigation could promote the growth of young apple trees. Nonetheless, the ability of large-scale fumigation to improve crop yield still requires further study by monitoring dynamic changes in soil microorganisms in the field. We speculate that the soil microbial environment may recover after dazomet fumigation in a direction that is conducive to crop growth and is friendly to the environment. However, the potential environmental burden imposed by subtle changes in soil microorganisms during the restoration process cannot be ignored.

\section{Declarations}

Ethics approval and consent to participate Not applicable.

Consent for publication Not applicable.

Competing interests The authors declare that we have no known competing financial interests or personal relationships that could have appeared to influence the work reported in this paper.

Funding The research was supported by the ea0rmarked fund for the National Modern Agro-industry Technology Research System of China (CARS-27), the National Natural Science Foundation of China (32072510), and Shandong Agricultural Major Applied Technology Innovation Project (SD2019ZZ008); Taishan Scholar Funded Project (NO.ts20190923); Qingchuang Science and Technology Support Project of Shandong Colleges and Universities (2019KJF020); Natural Science Foundation of Shandong Province (ZR2020MC131); and Fruit innovation team in Shandong Province, China (SDAIT-06-07).

Availability of data and materials The datasets used and/or analyzed during the current study are available from the corresponding author on reasonable request. The raw reads were deposited into the NCBI Sequence Read Archive (SRA) database (Accession Number: SRP313044).

Authors' contributions RC: Designed the study; Data curation; Software; Writing - original draft; Writing review \& editing. WTJ: Pot and Field sampling; Analyzed the data. SZX: Determination of soil physicochemical properties. HF, XSC, XS and CMY: Literature search and analyses. ZQM: Funding acquisition; Project administration; Resources; Supervision. All authors read and approved the final manuscript.

\section{References}

1. Aranda S, Montes-Borrego M, Jimenez-Diaz R, Landa BB (2011) Microbial communities associated with the root system of wild olives (Olea europaea L. subsp europaea var. sylvestris) are good reservoirs of bacteria with antagonistic potential against Verticillium dahliae. Plant Soil 343:329345, http://dx.doi.org/10.1007/s11104-011-0721-2

2. Ashworth DJ, Yates SR (2016) An Improved Method for Determination of Fumigant Degradation Half-Life in Soil. Soil Sci Soc Am J 80:64-68, http://dx.doi.org/10.2136/sssaj2015.07.0249 
3. Ayankojo IT, Morgan KT, Kadyampakeni DM, Liu GD (2020) Tomato Growth, Yield, and Root Development, Soil Nitrogen and Water Distribution as Affected by Nitrogen and Irrigation Rates on a Florida Sandy Soil. Hortscience 55:1744-1755, http://dx.doi.org/10.21273/HORTSCI15177-20

4. Bolger AM, Lohse M, Usadel B (2014) Trimmomatic: a flexible trimmer for Illumina sequence data. Bioinformatics 30:2114-2120, http://dx.doi.org/10.1093/bioinformatics/btu170

5. Bulgarelli D, Schlaeppi K, Spaepen S, van Themaat EVL, Schulze-Lefert P (2013) Structure and Functions of the Bacterial Microbiota of Plants. Annu Rev Plant Biol 64:807-838. http://dx.doi.org/10.1146/annurev-arplant-050312-120106

6. Cha S, Kim J, Choi IG, Choi J, Han H, Koo N, Kim YS (2019) Pre-Plant Fumigation of Soils for Nematode Control Affects the Seedling Production and Morphological Properties of Pine and Larch Seedlings. Forests 10, http://dx.doi.org/10.3390/f10100843

7. Chen BS, Du KQ, Sun C, Vimalanathan A, Liang XL, Li Y, Wang BH, Lu XM, Li LJ, Shao YQ (2018) Gut bacterial and fungal communities of the domesticated silkworm (Bombyx mori) and wild mulberryfeeding relatives. Isme J 12:2252-2262, https://doi.org/10.1038/s41396-018-0174-1

8. Degens BP, Schipper LA, Sparling GP, Vojvodic-Vukovic M (2000) Decreases in organic C reserves in soils can reduce the catabolic diversity of soil microbial communities. Soil Biol Biochem 32:189196, https://doi.org/10.1016/S0038-0717(99)00141-8

9. Deng XH, Zhang N, Shen ZZ, Zhu CZ, Li R, Salles JF, Shen QR (2020) Rhizosphere bacteria assembly derived from fumigation and organic amendment triggers the direct and indirect suppression of tomato bacterial wilt disease. Appl Soil Ecol 147. https://doi.org/10.1016/j.apsoil.2019.103364

10. Dong LL, Xu J, Feng GQ, Li XW, Chen SL (2016) Soil bacterial and fungal community dynamics in relation to Panax notoginseng death rate in a continuous cropping system. Sci Rep-Uk 6, https://doi.org/10.1038/srep31802

11. Du LT, Huang BJ, Du NS, Guo SR, Shu S, Sun J (2017) Effects of Garlic/Cucumber Relay Intercropping on Soil Enzyme Activities and the Microbial Environment in Continuous Cropping. Hortscience 52:78-84, https://doi.org/10.21273/HORTSCI11442-16

12. Fang WS, Wang XL, Huang B, Zhang DQ, Liu J, Zhu JH, Yan DD, Wang QX, Cao AC, Han QL (2020) Comparative analysis of the effects of five soil fumigants on the abundance of denitrifying microbes and changes in bacterial community composition. Ecotox Environ Safe 187. https://doi.org/10.1016/j.ecoenv.2019.109850

13. Friedrich MW (2011) Microbial communities, structure, and function, in: Encyclopaedia of geobiology: encyclopaedia of earth sciences series, pp. 592-595

14. Gdanetz K, Benucci GMN, Pol NV, Bonito G (2017) CONSTAX: a tool for improved taxonomic resolution of environmental fungal ITS sequences. Bmc Bioinformatics 18. https://doi.org/10.1186/s12859-017-1952-x

15. Gil SV, Meriles JM, Conforto C, Figoni G, Basanta M, Lovera E, March GJ (2009) Field assessment of soil biological and chemical quality in response to crop management practices. World J Microbiol Biotechnol 25:439-448, https://doi.org/10.1007/s11274-008-9908-y 
16. Gilreath JP, Santos BM (2004) Efficacy of methyl bromide alternatives on purple nutsedge (Cyperus rotundus) control in tomato and pepper. Weed Technol 18:341-345, https://doi.org/10.1614/WT-03086R2

17. Guo H, Mao ZQ, Jiang HX, Liu P, Zhou BQ, Bao ZZ, Sui JK, Zhou XY, Liu XL (2014) Community analysis of plant growth promoting rhizobacteria for apple trees. Crop Prot 62:1-9. https://doi.org/10.1016/j.cropro.2014.03.020

18. Harris DC (1991) A comparison of dazomet, chloropicrin and methyl bromide as soil disinfestants for strawberries. J Hortic Sci 66:51-58, https://doi.org/10.1080/00221589.1991.11516124

19. Hollister EB, Hu P, Wang AS, Hons FM, Gentry TJ (2013) Differential impacts of brassicaceous and nonbrassicaceous oilseed meals on soil bacterial and fungal communities. Fems Microbiol Ecol 83:632-641, https://doi.org/10.1111/1574-6941.12020

20. Huang Y, Xiao X, Huang HY, Jing JQ, Zhao HJ, Wang L, Long XE (2018) Contrasting beneficial and pathogenic microbial communities across consecutive cropping fields of greenhouse strawberry. Appl Microbiol Biot 102:5717-5729, https://doi.org/10.1007/s00253-018-9013-6

21. Huang YH (2019) Illumina-based Analysis of Endophytic Bacterial Diversity of four Allium species. Sci Rep-Uk 9, https://doi.org/10.1038/s41598-019-51707-7

22. Ingram LJ, Schuman GE, Stahl PD, Spackman LK (2005) Microbial respiration and organic carbon indicate nutrient cycling recovery in reclaimed soils. Soil Sci Soc Am J 69:1737-1745. https://doi.org/10.2136/sssaj2004.0371

23. Larkin RP (2003) Characterization of soil microbial communities under different potato cropping systems by microbial population dynamics, substrate utilization, and fatty acid profiles. Soil Biol Biochem 35:1451-1466, https://doi.org/10.1016/S0038-0717(03)00240-2

24. Li J, Huang B, Wang QX, Li Y, Fang WS, Han DW, Yan DD, Guo MX, Cao AC (2017) Effects of fumigation with metam-sodium on soil microbial biomass, respiration, nitrogen transformation, bacterial community diversity and genes encoding key enzymes involved in nitrogen cycling. Sci Total Environ 598:1027-1036, https://doi.org/10.1016/j.scitotenv.2017.02.058

25. Li J, Huang B, Wang QX, Li Y, Fang WS, Yan DD, Guo MX, Cao AC (2017) Effect of fumigation with chloropicrin on soil bacterial communities and genes encoding key enzymes involved in nitrogen cycling. Environ Pollut 227:534-542. https://doi.org/10.1016/j.envpol.2017.03.076

26. Liu XM, Cheng XK, Wang HY, Wang KY, Qiao K (2015) Effect of fumigation with 1,3-dichloropropene on soil bacterial communities. Chemosphere 139:379-385. https://doi.org/10.1016/j.chemosphere.2015.07.034

27. Magoc T, Salzberg SL (2011) FLASH: fast length adjustment of short reads to improve genome assemblies. Bioinformatics 27:2957-2963, https://doi.org/10.1093/bioinformatics/btr507

28. Maluin FN, Hussein MZ, Yusof NA, Fakurazi S, Idris AS, Hilmi NHZ, Daim LDJ (2020) Phytotoxicity of chitosan-based agronanofungicides in the vegetative growth of oil palm seedling. Plos One 15, https://doi.org/10.1371/journal.pone.0231315 
29. Manici LM, Ciavatta C, Kelderer M, Erschbaumer G (2003) Replant problems in south tyrol: role of fungal pathogens and microbial population in conventional and organic apple orchards. Plant Soil 256:315-324, https://doi.org/10.1023/A:1026103001592

30. Mao LG, Jiang HY, Wang QX, Yan DD, Cao AC (2017) Efficacy of soil fumigation with dazomet for controlling ginger bacterial wilt (Ralstonia solanacearum) in China. Crop Prot 100:111116, https://doi.org/10.1016/j.cropro.2017.06.013

31. Mao LG, Yan DD, Wang QX, Li Y, Ouyang CB, Liu PF, Shen J, Guo MX, Cao AC (2014) Evaluation of the Combination of Dimethyl Disulfide and Dazomet as an Efficient Methyl Bromide Alternative for Cucumber Production in China. J Agr Food Chem 62:4864-4869. https://doi.org/10.1021/jf501255w

32. Mazzola M (1998) Elucidation of the microbial complex having a causal role in the development of apple replant. disease in Washington Phytopathology 88:930-938. https://doi.org/10.1094/PHYT0.1998.88.9.930

33. MBTOC., 2006. Report of the methyl bromide technical options committee. UNEP, Nairobi, Kenya 34. Mehrabi Z, McMillan VE, Clark IM, Canning G, Hammond-Kosack KE, Preston G, Hirsch PR, Mauchline TH (2016) Pseudomonas spp. diversity is negatively associated with suppression of the wheat takeall pathogen (vol 6, 29905, 2016). Sci Rep-Uk 6. https://doi.org/10.1038/srep29905

35. Nannipieri P, Giagnoni L, Renella G, Puglisi E, Ceccanti B, Masciandaro G, Fornasier F, Moscatelli MC, Marinari S (2012) Soil enzymology: classical and molecular approaches. Biol Fert Soils 48:743762, https://doi.org/10.1007/s00374-012-0723-0

36. Nelson SD, Ajwa HA, Trout T, Stromberger M, Yates SR, Sharma S (2013) Water and Methyl Isothiocyanate Distribution in Soil after Drip Fumigation. J Environ Qual 42:1555-1564. https://doi.org/10.2134/jeq2013.03.0072

37. Pii Y, Mimmo T, Tomasi N, Terzano R, Cesco S, Crecchio C (2015) Microbial interactions in the rhizosphere: beneficial influences of plant growth-promoting rhizobacteria on nutrient acquisition process. A review. Biol Fert Soils 51:403-415, https://doi.org/10.1007/s00374-015-0996-1

38. Pinto MR, Sá ACMD, Limongi CL, Rozental S, Santos A, Barreto-Bergter E (2004) Involvement of peptidorhamnomannan in the interaction of pseudallescheria boydii and HEp2 cells. Microbes Infect 6:1259-1267, https://doi.org/10.1016/j.micinf.2004.07.006

39. Qin HN (2010) China Checklist of higher plants, in the biodiversity committee of chinese academy of sciences. catalogue of life china. Ann Che Chi, (in Chinese)

40. Rabodonirina S, Rasolomampianina R, Krier F, Drider D, Merhaby D, Net S, Ouddane B (2019) Degradation of fluorene and phenanthrene in PAHs-contaminated soil using Pseudomonas and Bacillus strains isolated from oil spill sites. J Environ Manage 232:1-7. https://doi.org/10.1016/j.jenvman.2018.11.005

41. Roberts TR, Hutson DH, Lee PW, Nicholls PH, Plimmer JR (1999) Metabolic pathways of agrochemicals || methyl isothiocyanate and precursors. Royal Society of Chemistry, Cambridge, pp 1211-1224, https://doi.org/10.1039/9781847551375-01211 
42. Schutter ME, Sandeno JM, Dick R (2001) Seasonal, soil type, and alternative management influences on microbial communities of vegetable cropping systems. Biol Fertil Soils 34:397-410. https://doi.org/10.1007/s00374-001-0423-7

43. Scott DC, Wilson AK, Ross BK, Ingram AD, Lewter AT (2018) Complete genome sequence of a wildtype isolate of caulobacter vibrioides strain cb1. MRA 7. https://doi.org/10.1128/MRA.01153-18

44. Shao XX, Yang WY, Wu M (2015) Seasonal Dynamics of Soil Labile Organic Carbon and Enzyme Activities in Relation to Vegetation Types in Hangzhou Bay Tidal Flat Wetland. Plos One 10. https://doi.org/10.1371/journal.pone.0142677

45. Sharma SK, Sharma A, Rana S, Kumar N (2018) Evaluation of multi-nutrient extractants for determination of available P, K, and micronutrient cations in soil. J Plant Nutr 41:782-792. https://doi.org/10.1080/01904167.2018.1426019

46. Su L, Zhu H, Niu YC, Guo YX, Du XP, Guo JG, Zhang L, Qin C (2020) Phylogeny and taxonomic revision of Kernia and Acaulium (vol 10, 10302, 2020). Sci Rep-Uk 10. https://doi.org/10.1038/s41598-020-67347-1

47. Su H, Zhang H, Wang CX, Huang JQ, Shang JY, Zhang N, Wang D, Li K (2020) Grape Pruning Material Improves Root Development and Soil Microecology in 'Shine Muscat' Grape Soils. Hortscience 55:2011-2011+, https://doi.org/10.21273/HORTSCI15400-20

48. Wang Y, Qin Y, Kot W, Zhang F, Rensing C (2016) Genome sequence of selenium-solubilizing bacterium caulobacter vibrioides t5m6. Genome Announcements 4:e01721-e01715. https://doi.org/10.1128/genomeA.01721-15

49. Widnyana IK, Javandira C (2016) Activities Pseudomonas spp. and Bacillus sp. to stimulate germination and seedling growth of tomato plants. Agr An Agr Sci Pro 9:419-423. https://doi.org/10.1016/j.aaspro.2016.02.158

50. Wu J, Chen J (2016) Determination of soil organic matter by potassium dichromate volumetric method - heating method. China's high-tech enterprises 26:11-12. (in chinese)

51. Xue XR, Mai WX, Zhao ZY, Zhang K, Tian CY (2017) Optimized nitrogen nitrogen fertilizer application enhances absorption of soil nitrogen and yield of castor with drip irrigation under mulch film. Ind Crop Prod 95:156-162

52. Yakabe LE, Parker SR, Kluepfel DA (2010) Effect of pre-plant soil fumigants on Agrobacterium tumefaciens, pythiaceous species, and subsequent soil recolonization by $A$. tumefaciens. Crop Prot 29:583-590, https://doi.org/10.1016/j.cropro.2010.01.001

53. Yamamoto T, Ultra Jr VU, Tanaka S, Sakurai K, Iwasaki K (2008) Effects of methyl bromide fumigation, chloropicrin fumigation and steam sterilization on soil nitrogen dynamics and microbial properties in a pot culture experiment. Soil Sci Plant Nutr 54:886-894. https://doi.org/10.1111/j.1747-0765.2008.00319.x

54. Yan DD, Wang QX, Li Y, Ouyang CB, Guo MX, Cao AC (2017) Analysis of the inhibitory effects of chloropicrin fumigation on nitrification in various soil types. Chemosphere 175:459-464. https://doi.org/10.1016/j.chemosphere.2017.02.075 
55. Yan DD, Wang QX, Mao LG, Ma TT, Li Y, Ouyang CB, Guo MX, Cao AC (2015) Interaction between nitrification, denitrification and nitrous oxide production in fumigated soils. Atmos Environ 103:8286, https://doi.org/10.1016/j.atmosenv.2014.09.079

56. Yao H, He Z, Wilson MT, Campbell CD (2000) Microbial biomass and community structure in a sequence of soils with increasing fertility and changing land use. Microb Ecol 40:223-237. https://doi.org/10.1007/s002480000053

57. Zasada IA, Halbrendt JM, Kokalis-Burelle N, LaMondia J, McKenry MV, Noling JW (2010) Managing nematodes without methyl bromide. Annu Rev Phytopathol 48:311-328. https://doi.org/10.1146/annurev-phyto-073009-114425

58. Zhang DL, Ji XX, Meng Z, Qi WZ, Qiao K (2019) Effects of fumigation with 1,3-dichloropropene on soil enzyme activities and microbial communities in continuous-cropping soil. Ecotox Environ Safe 169:730-736, https://doi.org/10.1016/j.ecoenv.2018.11.071

59. Zhang YJ, Zhao ZW, Li HC (2012) Tolerance and hyperaccumulation of heavy metals in roots of plants in mining areas. Soil 44:467-473. (in chinese)

60. Zheng WK, Sui CL, Liu ZG, Geng JB, Tian XF, Yang XY, Li CL, Zhang M (2016) Long-Term Effects of Controlled-Release Urea on Crop Yields and Soil Fertility under Wheat Corn Double Cropping Systems. Agron J 108:1703-1716, https://doi.org/10.2134/agronj2015.0581

\section{Figures}
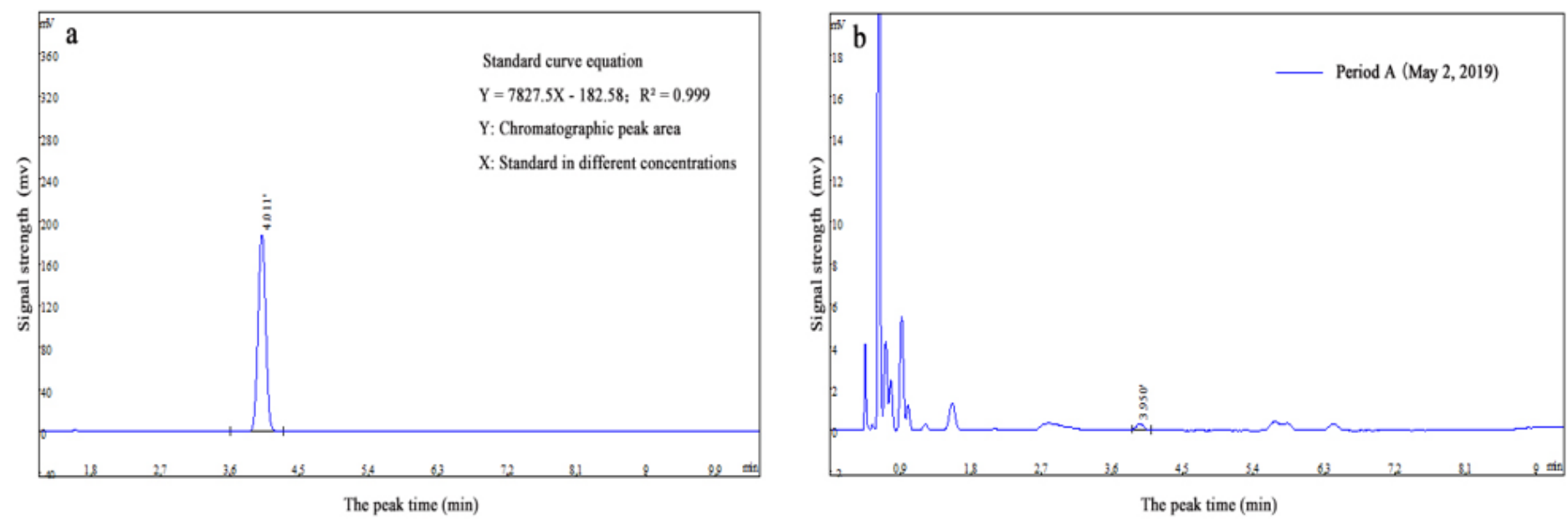

\section{Figure 1}

Figure a shows the chromatogram of the standard curve construction. The equation of the standard curve is made by using the standard substance (MITC) of different concentration and the corresponding peak area of the spectrum. Figure $b$ shows the chromatogram of three repeated samples of DZ. The peak area in the chromatogram can be obtained by software integration. MITC content in the sample can be calculated according to the known peak area, as shown in Table 2. 


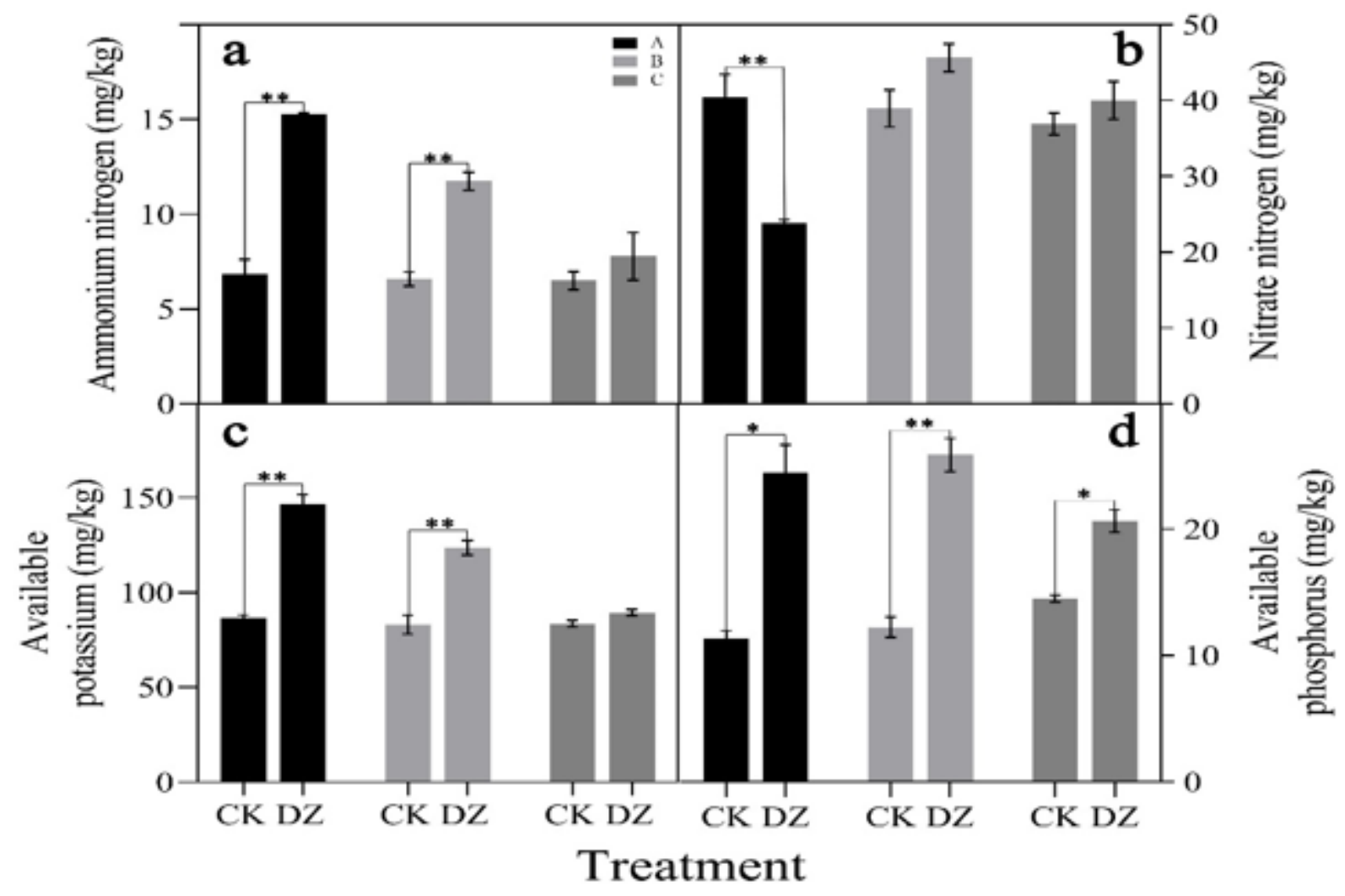

Figure 2

Soil nutrient availability at three time periods during the two years after dazomet fumigation: (a) ammonium nitrogen; (b) nitrate nitrogen; (c) available potassium; (d) fast available phosphorus. A = May 2, 2019; B = Sept. 10, 2019; C = Sept. 10, 2020; CK = untreated control (replant soil); DZ = Dazomet fumigated soil. A t-test was used to assess the significance of differences between the two samples in a given period. ${ }^{*} 0.01<P \leq 0.05,{ }^{\star *} 0.001<P \leq 0.01,{ }^{* \star * P} \leq 0.001$. Bars represent the mean $\pm \mathrm{SE}$ of three replicates. 


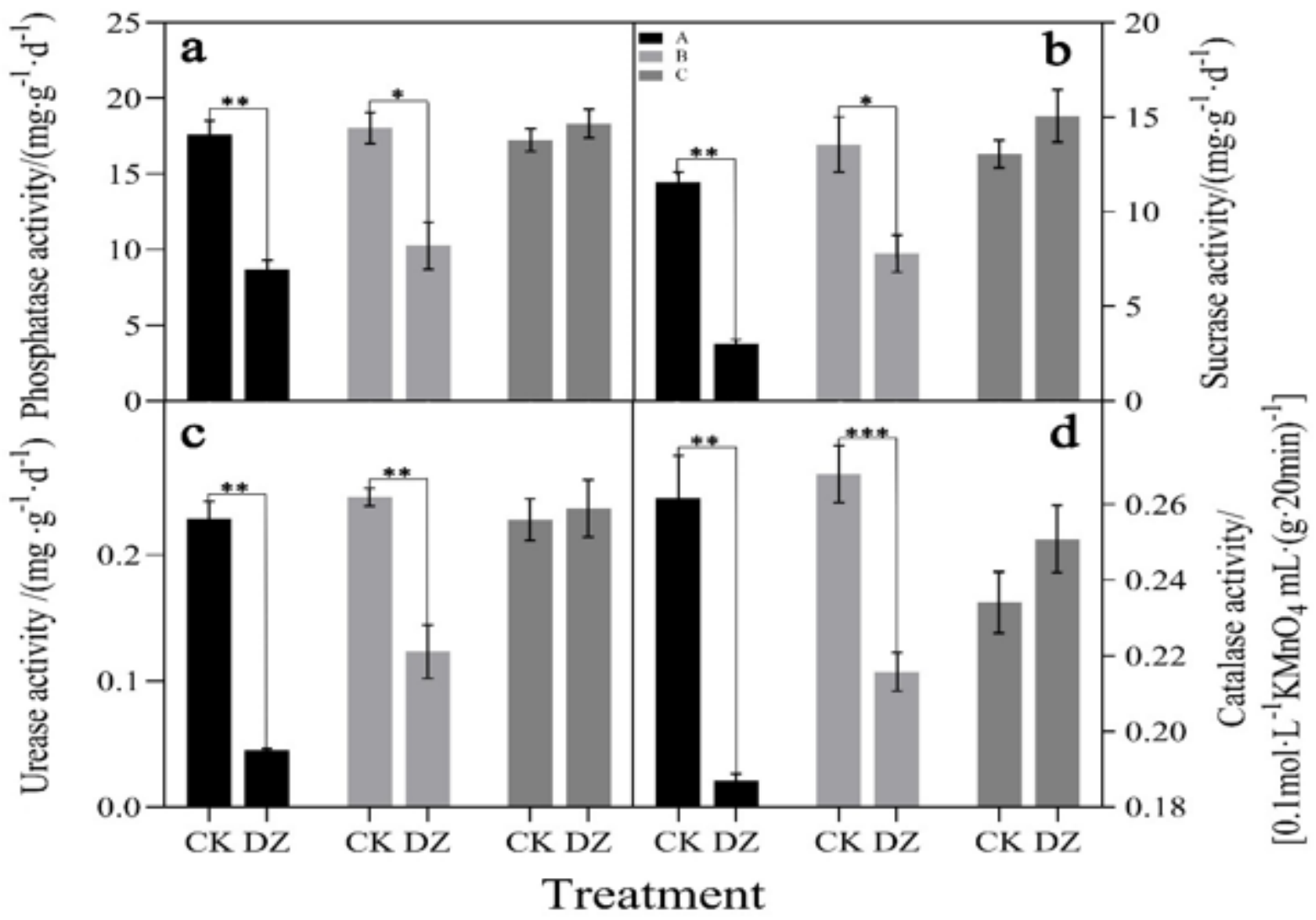

Figure 3

Soil enzyme activities at three time periods during the two years after dazomet fumigation: (a) phosphatase activity; (b) sucrase activity; (c) urease activity; (d) catalase activity. Letters and asterisks are as defined in Figure 1. 


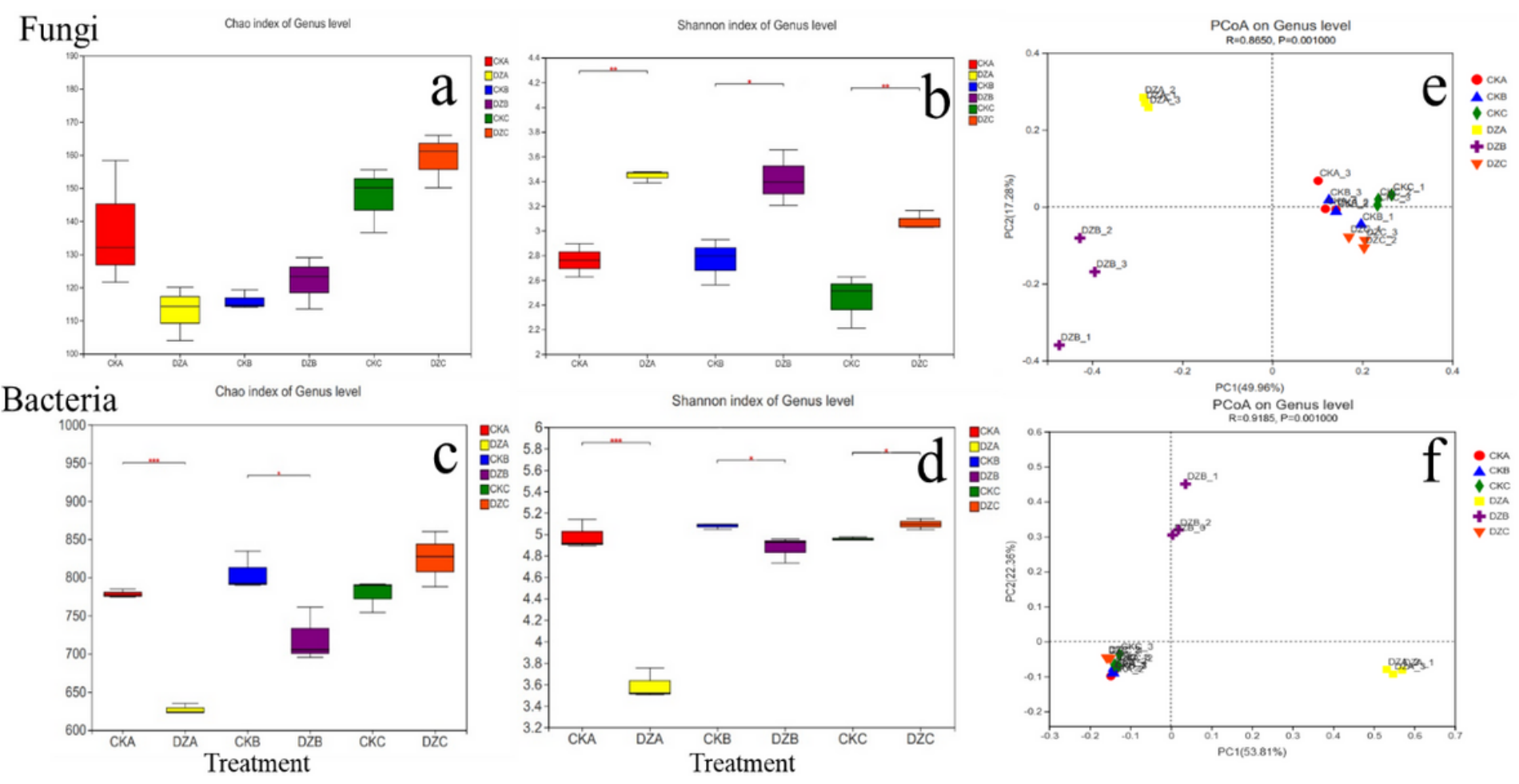

\section{Figure 4}

Alpha $(a-d)$ and beta $(e, f)$ diversity of soil fungi and bacteria at the genus level after dazomet fumigation of replant soil: (a) Chao indices of fungi; (b) Shannon indices of fungi; (c) Chao indices of bacteria; (d) Shannon indices of bacteria; (e) PCoA of fungi; (f) PCoA of bacteria. Student's t-test was used to assess differences in alpha and beta diversity between DZ fumigated soil and untreated replant soil (CK). The y-axis shows the exponential mean of each group. Principal Coordinate Analysis (PCoA) is based on the Bray-Curtis distance metric at the genus level, and the results are displayed as a scatter diagram. The $x$-axis and $y$-axis represent the first two principal axes, and the percentage represents the explanatory value of the principal axis towards the difference in sample composition. The scale of the $x-$ axis and $y$-axis is a relative distance measure that has no practical significance; different colors and shapes of points indicate different sample groups. The closer two sample points are, the more similar are the species compositions of the two samples. 

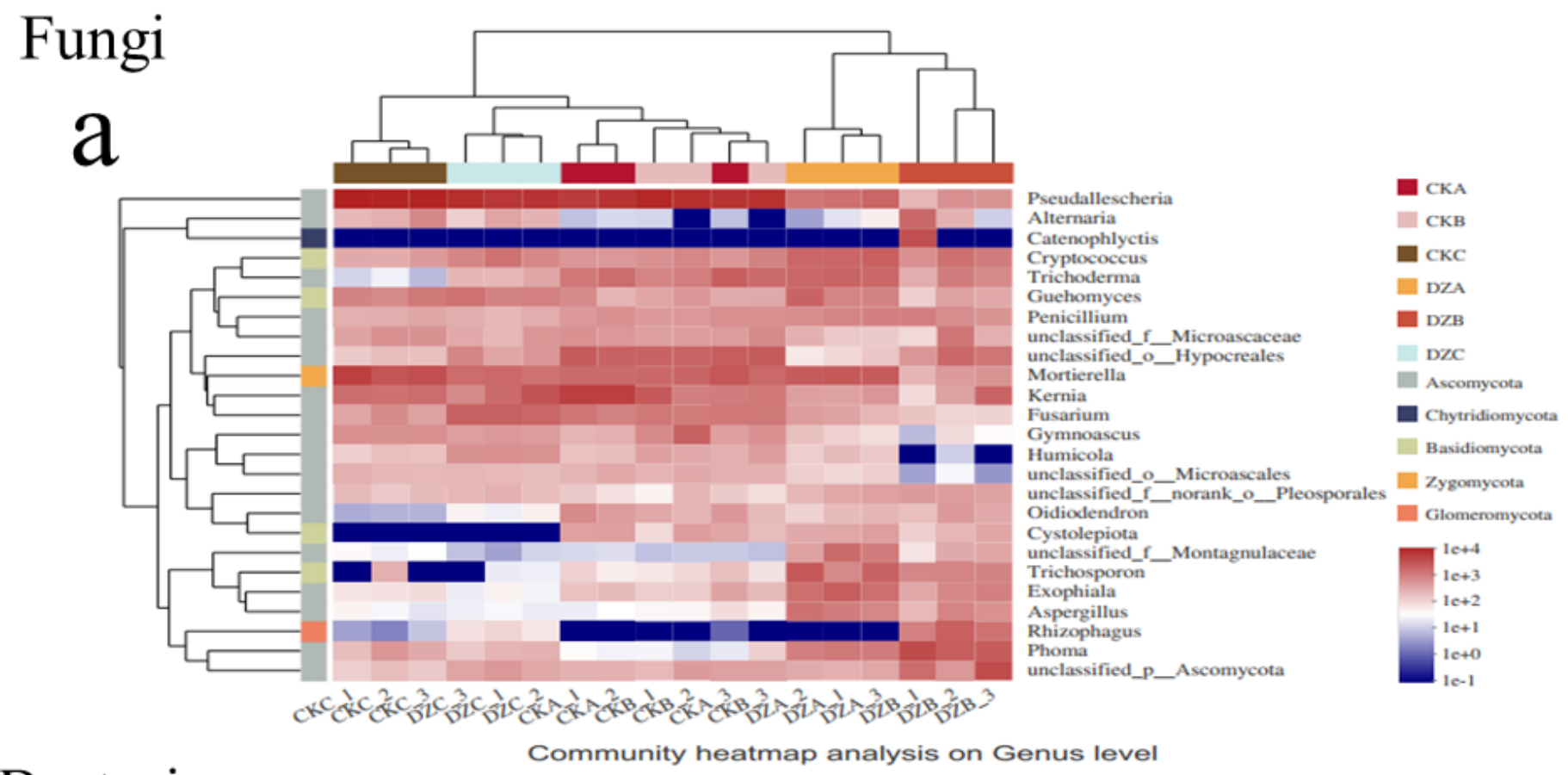

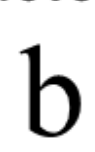

Bacteria

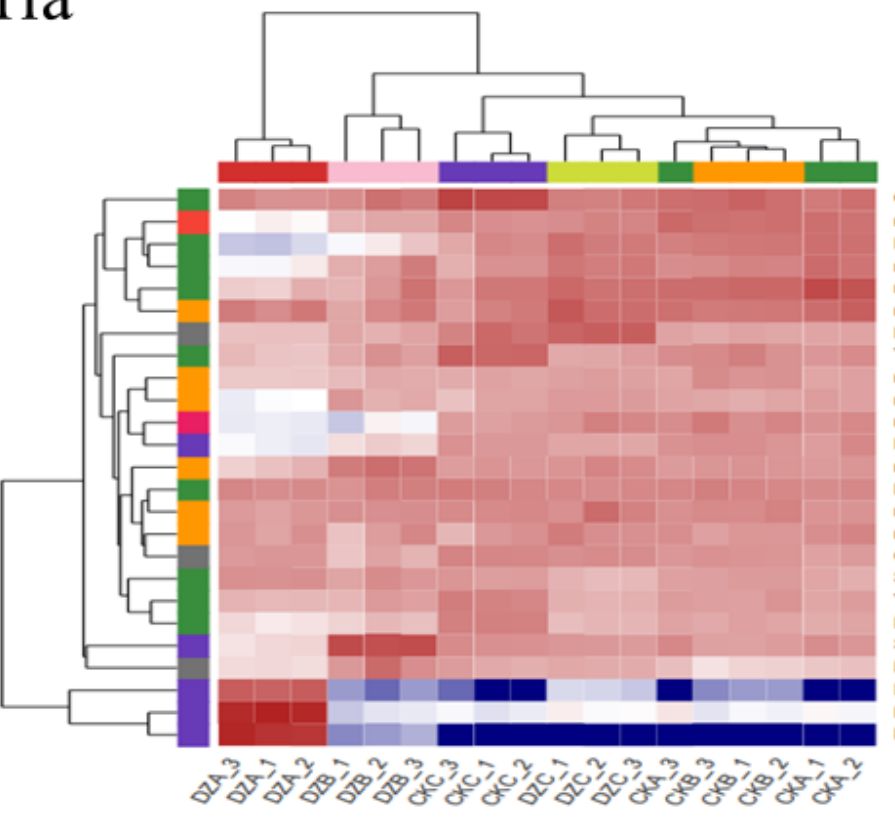

Clostridium_sensu_stricto_ 1

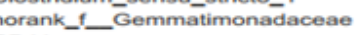

RB41

horank_f_Vicinamibacteraceae

horank_f_norank_o_-Vicinamibacterales

norank_f_norank_o_norank_c__KD4-96

Pseudarthrobacter

Terrisporobacter

norank_f - norank_o _norank_c_-TK10

horank_t_A4b

norank_t_-norank_o - Rokubacteriales

Pedomicrobium

norank_f_Roseiflexaceae

Bacillus

norank_f_JG30-KF-CM4S

horank_f_norank_o_norank_c__Gitt-GS-136

Gaiella

Sporosarcina

Turicibacter

Sphingomonas

Nocardioides

Hydrogenophaga

Pseudomonas

Methyloversatilis

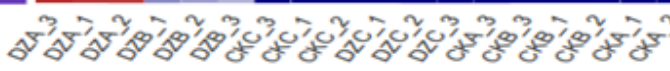

CKA

-

-

DIZA

DZB

DZC

Eirmicutes

- Gemmatimonadota

Acidobacteriota

Chloroflexi

- Actinobacteriota

Methylomirabilota

- Proteobacteria

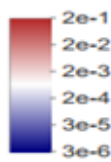

\section{Figure 5}

Hierarchical clustering and annotated heatmaps of the fungal and bacterial communities in different samples at the genus level after dazomet fumigation of replant soil $(a, b)$. Different color intensities represent the normalized relative abundance of the bacterial genera in each row. Each treatment was replicated three times. DZA = period $A$ of dazomet fumigation; $D Z B$ = period $B$ of dazomet fumigation; $\mathrm{DZC}=$ period $\mathrm{C}$ of dazomet fumigation; $\mathrm{CKA}=$ period $\mathrm{A}$ of untreated control; $\mathrm{CKB}=$ period $\mathrm{B}$ of untreated control; $\mathrm{CKC}=$ period $\mathrm{C}$ of untreated control. 


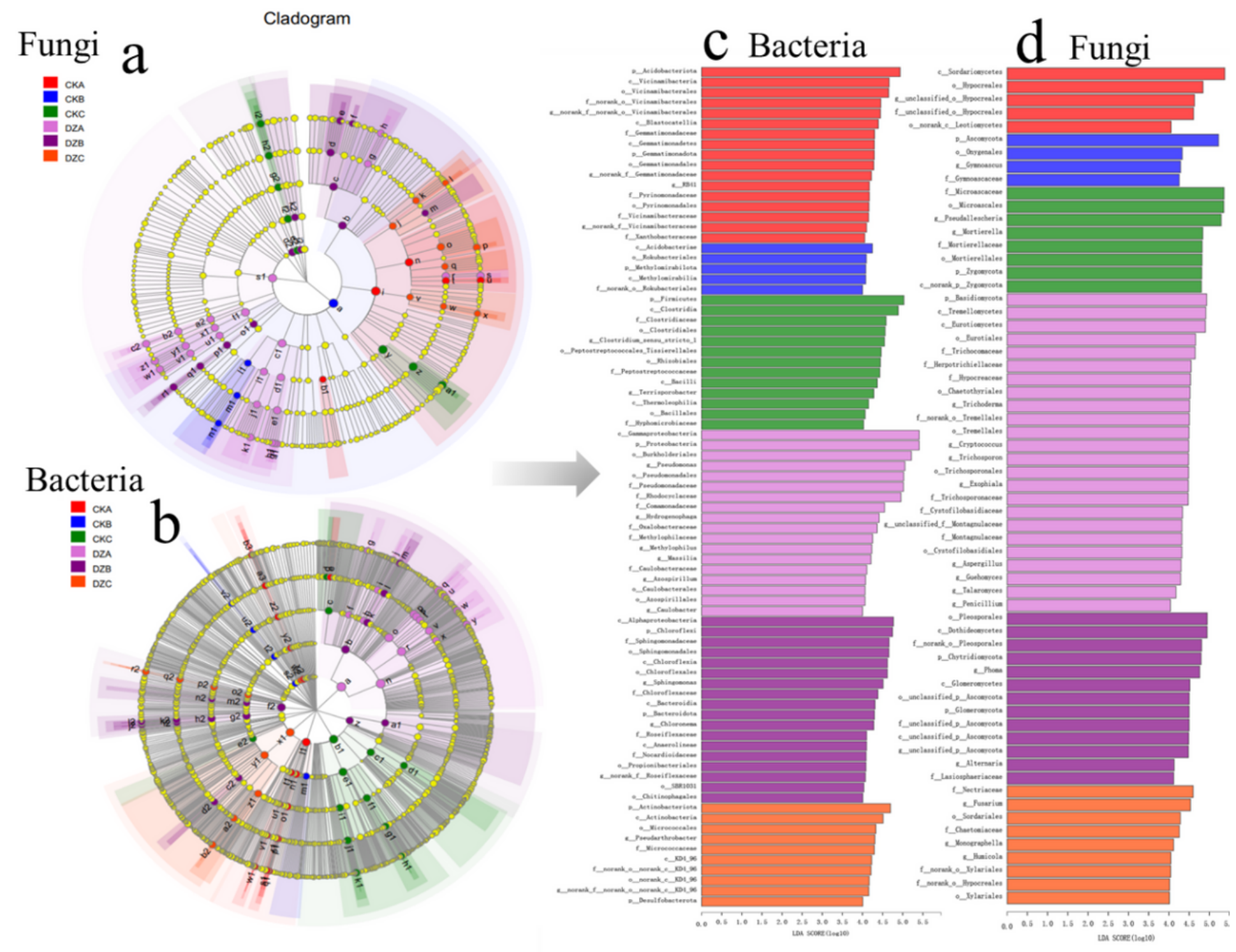

Figure 6

Different color nodes indicate microbial groups that are significantly enriched in the corresponding group and significantly influence inter-group differences $(a, b)$. LEfSe based on linear discriminant analysis (LDA) was used to estimate the influence of the abundance of each component (species) on the treatment differences $(c, d)$. LDA discriminant bar charts are used to identify significant microorganism groups in multiple treatments ( $L D A=4$, all-against-all). The species abundances of microbial groups with larger LDA scores have a greater influence on the difference between soil treatments. 

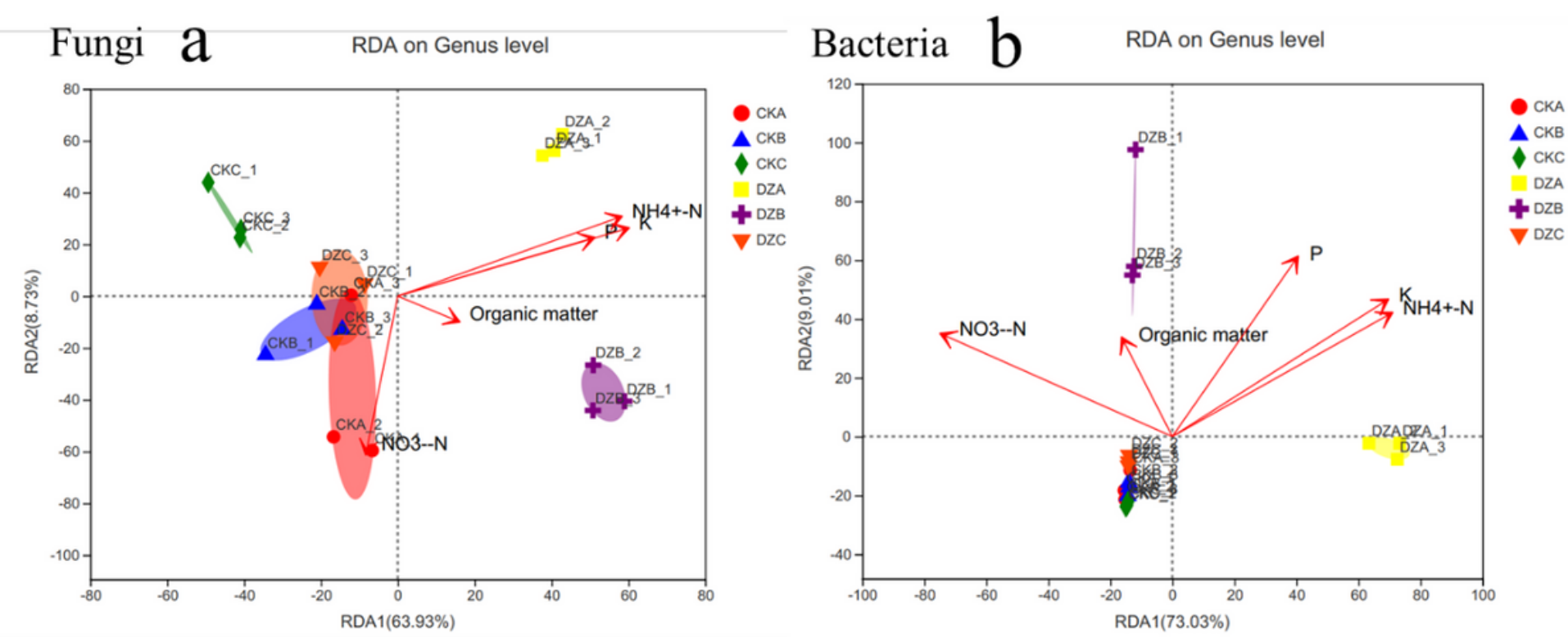

Figure 7

Points with different colors and shapes represent samples from different treatments and time periods. The red arrows represent quantitative environmental factors, and the lengths of the arrows represent the degree of impact of the environmental factors on the samples data. The angles of the arrows indicate positive and negative correlations (acute angle: positive correlation; obtuse angle: negative correlation; right angle: no correlation). Projection is made from the sample point to the arrows representing quantitative environmental factors. The distance from the projection point to the origin represents the relative influence of the environmental factor on the distribution of sample communities.

\section{Supplementary Files}

This is a list of supplementary files associated with this preprint. Click to download.

- GraphicalAbstract.png

- Supplementarymaterial.docx 